\title{
ASO Visual Abstract: Importance of Nodal Metastases Location in Pancreatoduodenectomy for Pancreatic Ductal Adenocarcinoma: Results from a Prospective Lymphadenectomy Protocol
}

Giuseppe Malleo, $\mathrm{MD}^{1}$ (1) , Laura Maggino, $\mathrm{MD}^{\mathbf{1}}$, Fabio Casciani, $\mathrm{MD}^{\mathbf{1}}$, Gabriella Lionetto, $\mathrm{MD}^{\mathbf{1}}$, Sara Nobile, MD ${ }^{1}$, Gianni Lazzarin, $\mathbf{M D}^{1}$, Salvatore Paiella, $\mathbf{M D}^{1}$, Alessandro Esposito, $\mathbf{M D}^{1}$, Paola Capelli, $\mathrm{MD}^{2}$, Claudio Luchini, $\mathrm{MD}^{2}$, Aldo Scarpa, $\mathrm{MD}^{2}$, Claudio Bassi, $\mathrm{MD}^{1}$, and Roberto Salvia, MD ${ }^{1}$

${ }^{1}$ Unit of General and Pancreatic Surgery, Department of Surgery, Dentistry, Gynecology and Pediatrics, G.B. Rossi Hospital, University of Verona, Verona, Italy; ${ }^{2}$ Section of Pathology, Department of Pathology and Diagnostics, University of Verona, Verona, Italy

Prospective implementation of a lymphadenectomy protocol in 424 pancreatoduodenectomies for cancer showed that first-echelon nodal dissection was sufficient for optimal staging. Nodal metastases occurred mostly at stations 13/14, although second-echelon involvement was frequent. Only station 14 and jejunal mesentery nodes involvement was prognostically relevant (https://doi.org/1 0.1245/s10434-022-11417-3).

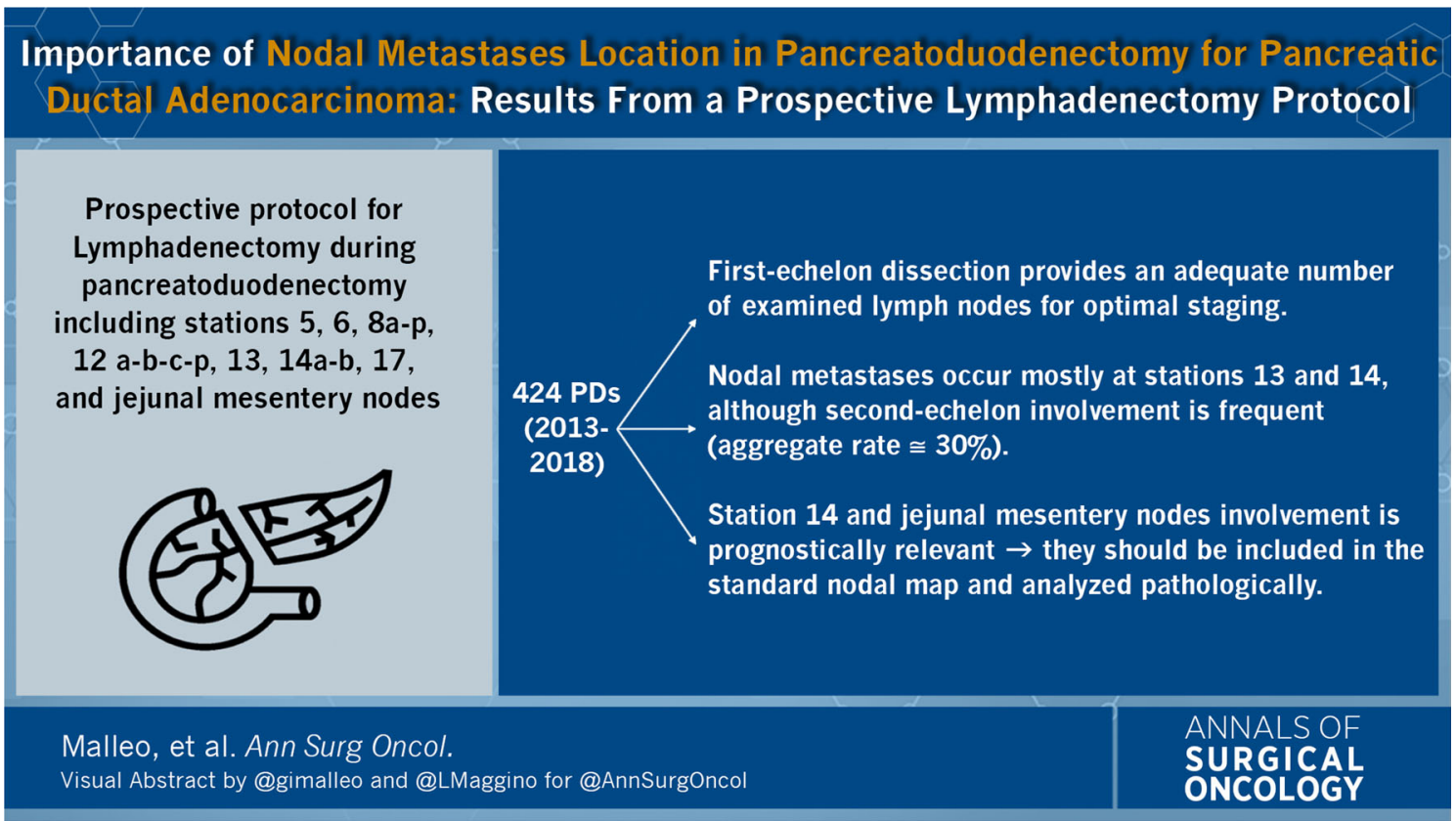

(C) Society of Surgical Oncology 2022

FUNDING None.

DISCLOSURE None.

R. Salvia, MD

Publisher's Note Springer Nature remains neutral with regard to e-mail: roberto.salvia@univr.it jurisdictional claims in published maps and institutional affiliations. 